\title{
DEVELOPMENT AND VALIDATION OF AN EDUCATIONAL HEARING CONSERVATION PROGRAMME FOR MALAYSIAN YOUTH: Bisinglah BEB!
}

\author{
Kamarul Akmal Ishak, Noraidah Ismail and Sarah Rahmat
}

Department of Audiology and Speech-Language Pathology, Kullliyah of Allied Health Sciences, International Islamic University Malaysia, 25200 Kuantan, Pahang, Malaysia.

Corresponding author: Noraidah Ismail

Email: noraidah@iium.edu.my

\begin{abstract}
Exposure to leisure noise among the youth has grown into a public health concern. It was reported that attitudes and behaviours are essential factors in determining how well someone takes care of their hearing. An educational hearing conservation programme $(E d H C P)$ can be an effective way to educate and to induce behavioural changes. The objective of this study is to develop and to validate a Malay version of EdHCP known as Bisinglah BEB! (in English: HEY! It's Loud!) targeting the Malaysian youth. The present study comprised of four phases, namely; i) content and module development, ii) content validation, iii) content modification, and iv) pre-testing. Five learning modules were developed; Module One (Sound energy), Module Two (Anatomy and hearing mechanisms), Module Three (Hearing loss), Module Four (How loud the sound), and Module Five (How to protect our hearing). The module and contents of the programme possessed good content validity result (S-CVI/Ave value at 0.935). Several modifications were done accordingly, and agreement among the participants in pre-testing was excellent (95-100\%). Bisinglah BEB! was informative and produced a high content-validity result. However, the effectiveness of the programme in changing attitude, knowledge, and behaviour towards noise exposure needs to be investigated before the real implementation in Malaysian youth.
\end{abstract}

Keywords: Education, Hearing loss, Noise, Leisure activities, Adolescent.

\section{INTRODUCTION}

Young adults are prone to loud music exposure through a variety of leisure activities. These activities might damage their hearing as a result of music exposure, also known as music-induced hearing loss ${ }^{1}$. With the current world globalization and modernisation, there has been a drastic change in youth's behaviour in listening to music. It was proven that the rapid growth in the number of young people exposed to loud sounds from the activities of listening music and engagement in recreational noise-related activities had been concretely observed in the previous studies ${ }^{2-6}$.

In 2015, the World Health Organization (WHO) released an article stating that approximately 1.1 billion young people worldwide were at risk of hearing loss because of hazardous listening practices $^{7}$. The report estimated that nearly $50 \%$ of the children and young adults from the age of 12 to 35 years old were listening to a high level of sound when using personal listening device (PLD). Additionally, $40 \%$ of them were exposed to hazardous sound levels when frequenting discotheques, clubs, rock concerts, and bars. In Asia, Peng et al. ${ }^{8}$ found that $14 \%$ of young adults in China were affected by excessive music exposure. Meanwhile, a study in Singapore revealed that one out of six university students was at risk of developing noise-induced hearing loss (NIHL) due to poor listening practices ${ }^{9}$.
Several factors contributing to the listening attitudes and behaviours of the youth. These factors include psychosocial differences such as age, gender, and race ${ }^{9-11}$. Apart from psychosocial factors, socio-demographic factors include socioeconomic status or poverty ${ }^{12}$. These factors influence the pro-attitudes towards noise (poor listening attitude) among young adults ${ }^{13}$.

NIHL is insidious, but with prolonged exposure, it will affect the communicative ability and reduce the cognitive performance among children and students ${ }^{14-15}$, which later on will lead to a negative impact on both individual and country ${ }^{16}$. Huddle et al. ${ }^{17}$ estimated that hearing loss causes a loss of billions of dollars per year worldwide, including medical expenditures, loss of income and productivity, and caregiver costs. Hence, substantial work should be done to give exhaustive education in improving the youth's attitude and behaviour towards hazardous noise exposure $^{18}$. Nevertheless, there is still a lack of, or rather, a missing educational hearing conservation programme (EdHCP) targeting the Malaysian youth.

The objective of this study is to pioneer a Malay EdHCP known as Bisinglah BEB! (in English: HEY! It's Loud!) for Malaysian youth, primarily to caution them against dangerous noise exposure as well as to educate them on hearing preventive measures. The 50-minutes newly developed 
classroom programme contained five modules; i) Sound energy, ii) Anatomy and physiology of hearing, iii) Hearing loss, iv) How loud the sound, and v) How to protect our hearing. All modules were presented through a lecture-based format with a combination of various interactive activities to ensure that the participants easily comprehended the topics.

\section{METHODS}

The development of the Bisinglah BEB! was conducted in four phases. These four-phases Type 1 Design and Development Research approach (DDR) was implemented to develop the contentspecific knowledge pertaining to the learning modules and contents of the Bisinglah BEB!. DDR introduced by Richey and Klein ${ }^{19}$, is based on the concept that the practice of design or development in research project should be conducted systematically. Through an organised design and procedure, the scientific method would be employed to make it easier for field practitioners (Audiologist, school nurse or teacher) to understand the development process of the Bisinglah BEB!.

Phase 1 was the development of the module and content slides by reviewing the contents of available EdHCP in literature. A content validity assessment by a panel of experts was conducted in Phase 2. Based on the content validity result and panel expert discussions, module and content modifications were performed in Phase 3. Upon modifications, a pre-testing was conducted to the target group in Phase 4 . The final revision was determined by an agreement and from comments from participants in the pre-testing phase (refer Figure 1). The procedure of this current study was approved by the International Islamic University (IIUM) research committee (IREC 2019-181), and permissions from the Ministry of Education and the Penang Education Department were acquired in advance.

\section{Phase 1 (Module and content development)}

\section{Programme reviewing}

The researchers in this study reviewed related literature on EdHCP conducted in other countries. Based on accessibility, objectives, and intervention approaches, only four programmes were selected, as they provided a full programme description: i) Cheers for Ears, ii) Dangerous Decibels ${ }^{\circledR}$, iii) Hear4Tomorrow (H4T), and iv) It's a Noisy Planet. Protect Their Hearing ${ }^{\circledR}$. All materials were obtained and reviewed in terms of the teaching approaches, learning modules, contents, activities, and timeframe (programme duration). Although not all reviewed programmes were targeted for youth, their curricula and materials could be used as references in developing the Bisinglah BEB!. Furthermore, specific strategies and possible challenges may face in implementing the Bisinglah BEB! should be take into consideration to ensure programme sustainablility ${ }^{20}$.

\section{The theoretical and conceptual framework}

The Health Belief Model (HBM) and the Social Cognitive Theory (SCT) were used as the intervention theories in developing the modules and contents of Bisinglah BEB!. The HBM emphasises several factors to engage an individual to stay healthy such as perceived susceptibility, perceived severity, perceived benefit, perceived barrier and self-efficacy, and cues to action ${ }^{21}$. Meanwhile the SCT states that the behavioural health of an individual is influenced by the relationships, attitudes, and behaviours of others $^{22}$.

The development of the modules of Bisinglah BEB! followed the five successful modules as specified by Roger et al. ${ }^{23}$; i) physiology of noise and the sources of noise, ii) anatomy and physiology of the ear and the cochlear outer hair cell damage, iii) effects of noise on hearing, iv) warning signs of $\mathrm{NIHL}$, and v) specific recommendations to prevent NIHL. Another topic recommended by Lass et al. ${ }^{24}$ and Anderson ${ }^{25}$ that was also included in the module were the types of hearing loss and their causes, and the specific noise that was harmful to hearing.

Figure 2 shows how the modules of Bisinglah BEB! were constructed based on these two models. With regard to the $\mathrm{HBM}$, the researchers hypothesised that if the participants; i) regarded themselves as susceptible to NIHL, ii) believed that NIHL would potentially have adverse effects, iii) believed that a course of action available would be beneficial in reducing either their susceptibility to or severity of the NIHL, and iv) believed that the benefits of taking actions outweighed the cons, then they would be more likely to take action to reduce their risk of getting NIHL.

For the concept of perceived susceptibility, the participants would be made aware that excessive noise exposure would cause hearing damage. Thus, Module One, Module Two, and Module Four addressed the means in which the energy of excessive noise could damage our hearing. These modules helped the participants understand the effect of loud noise to the ears, and in turn, this understanding would change their belief on dangerous noise exposure. Module Three discussed the nature of hearing loss and its consequences. Under the concept of perceived severity and perceived benefits, the participants would be prompted to consider that hearing loss had negative consequences and preventing hearing loss was crucial. Lastly, Module Five educated participants on how to protect their hearing by using appropriate hearing protection devices (HPDs) and other hearing preventive techniques. Under the concept of perceived 
barrier, practical sessions on earplugs would help the participants to change their negative thoughts over the use of HPDs, e.g. it is expensive, difficult to use, uncomfortable to be used, or any other negative attitudes towards the use of HPDs. Under the concept of self-efficiency, the participants were encouraged to believe that they could use HPDs effectively. They would be able to change the sound environment or their listening habits using two simple solutions; i) moving away from the sound source and ii) reducing the volume of the PLD.

Meanwhile, the SCT stated that personal and environmental factors were considered to interact with each other. Through the implementation of the current programme, the youth's attitudes, behaviours, and knowledge towards noise could be improved. At the same time, encouragement from peers and environmental factors could boost their motivation to maintain a healthy hearing behaviour (cues to action).

\section{Initial version of Bisinglah BEB!}

The initial version of Bisinglah BEB! had seven components, which included an introduction, five learning modules, and a learning outcome or a short quiz. At first, 26 content slides were generated. All the materials, including the animation, video clips, and images, were adapted from other resources with official permissions granted.

In Module One, the participants learned that the energy from a loud sound was hazardous and damaging to the ears. The participants partook in a practical session using their voice. They touched their throats and loudly said 'aaaaa', followed by a soft 'aaaaa'. The purpose of this activity was to educate the participants about the persistence of the energy of vibrations, even at a low sound range. In addition, the educator also introduced and discussed about the three steps of hearing preventive measures; i) moving away from the source, ii) reducing the volume, and iii) wearing a hearing protection device. In Module Two, the participants learned about the mechanism in which the energy of a loud sound inflicted damages upon the outer hair cells in the ear. By understanding the way different parts of the ear functioned, the participants would know how noise could harm their hearing. Module Three explained the degree of hearing loss and the adverse effects of hearing loss on an individual's daily life. The severities and impacts of hearing loss were discussed between the educator and the participants, and they were encouraged to participate in the discussion session.

Following that, in Module Four the participants learned how to identify the sources of noise that might be harmful to their hearing and other factors contributing to the severity of NIHL. A decibel scale was displayed, and the participants learned about the three contributing factors of $\mathrm{NIHL}$ severity; i) intensity (loudness) of the sound, ii) duration of exposure, and iii) frequency of exposure. A 'noise meter' activity developed by the National Institute of Occupational Safety and Health (NIOSH) was also conducted. The participants listened to different types of noise, such as a whispering sound, a telephone ringing, a bulldozer, a hand drill, and an ambulance siren, while they simultaneously watched the noise meter needle on the screen bounced up and down according to the noise level being played. In addition to the NIOSH noise meter activity, a sound measurement activity using a food processor and a sound level meter was also included. The theory of reducing noise exposure level by moving away from the sound source was proven afterwards. In Module Five, the participants were guided on how to choose and to use appropriate HPDs. The participants learned how to protect their hearing using HPDs as well as to understand the different types of HPDs (earplugs and earmuffs). Earplugs were freely provided during the practical session to ensure that they learned how to fit the earplugs properly.

To measure the learning outcome, a short quiz or learning outcome was distributed after the programme delivery. The questions were divided into two sections. In Section A, the participants were requested to match the ten names of the ear structure based on the diagram given, while Section B consisted of eight close-ended statements and two open-ended questions. The programme timeframe (presentation and quiz) was estimated to be around 60 minutes per session, which was considered appropriate as it did not exceed the typical classroom learning duration.

\section{Phase 2 \& 3 (Content validation and content modification)}

\section{Expert recruitment}

Ten professionals were recruited into an expert panel based on a purposive sampling technique, comprising of a senior lecturer of audiology from Universiti Kebangsaan Malaysia (UKM), an otorhinolaryngologist, three senior audiologists from the Ministry of Health, two senior audiologists from the Ministry of Education and three Dangerous Decibels ${ }^{\circledR}$ educators. Senior audiologists referred to those who were at least a bachelor's degree holder in the field of audiology with ten years of working experience. The selected experts must be able to communicate in Bahasa Malaysia and were literate in the language because the programme was developed in Bahasa Malaysia. These experts must also have at least three years of experience being involved in hearing conservation programmes. All panel experts were contacted either by a phone call or by email. 


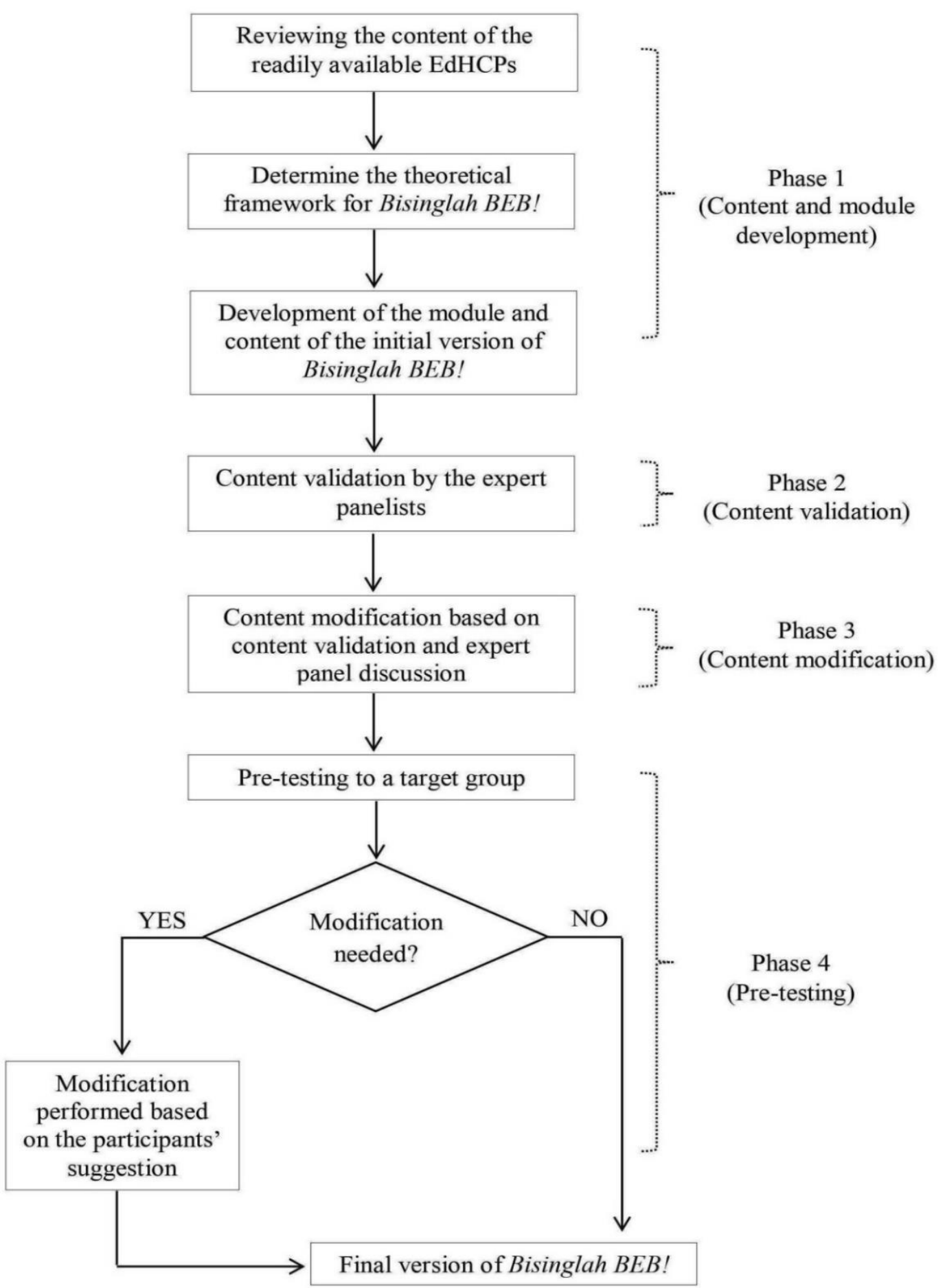

Figure 1. Research procedure 


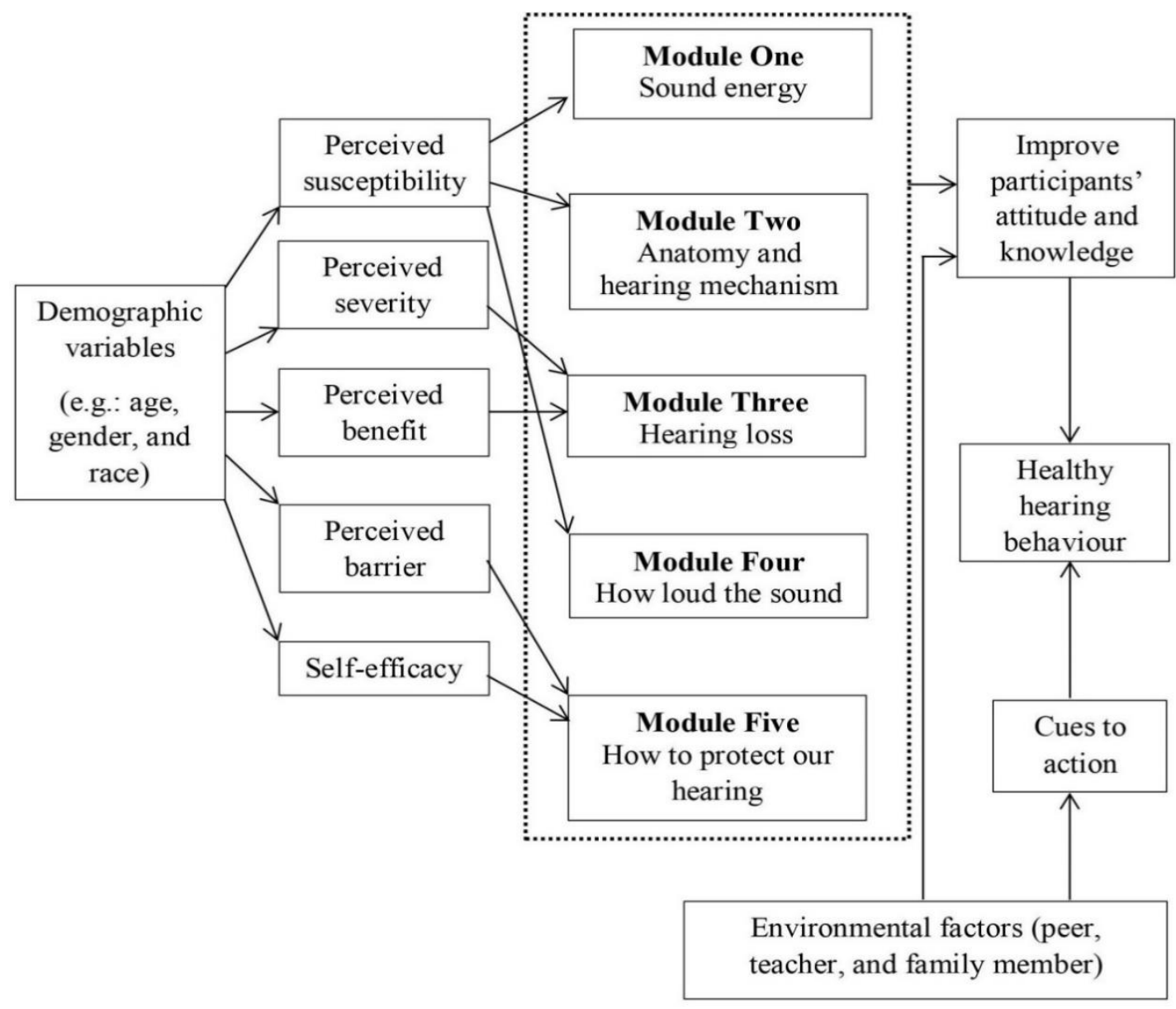

Figure 2. The modules and contents of Bisinglah BEB! were constructed based on the Health Belief Model and the Social Cognitive Theory

\section{Procedure}

A set of documents consisting of the programme description and the rating questionnaire was submitted to the respective panel experts. The panel evaluated the content slides, materials and activities, the layout, and the list of questions in the learning outcome/quiz section based on their relevancy and essentiality. The need for modification or revision was based on the responses and comments from the panel of experts. Modifications were focused on two aspects; content and layout. The content modification involved the revision of the content slides, including the correctness of the grammar used, while the layout modification required the rearrangement of the content slides.

\section{Data analysis}

The content validity was analysed based on the content validity index (CVI) and content validation ratio (CVR). First, the score of CVR was calculated. The score for CVR ranges from 1 and 1 , in which the highest score indicates excellent agreement among the panel of experts. In order for the item/content slide to be accepted, a minimum value of CVR needed to be determined based on the Lawshe table ${ }^{26}$. A minimum CVR value of 0.62 was required for the item/content slide to be accepted. The equation for the CVR is shown in Equation 1.

\section{A) Equation 1}

Content validity ratio for each it

$$
=\frac{N e-\frac{N}{2}}{\frac{N}{2}}
$$

Ne: the number of experts giving rating $3, N$ : Total number of experts.

Next, the CVI values were determined based on Lynn's criteria ${ }^{27}$. The $\mathrm{CVI}$ value can be determined by item-level (I-CVI) and overall scale average (S$\mathrm{CVI} /$ Ave). A minimum I-CVI value of 0.78 and a S$\mathrm{CVI} /$ Ave valued at more than 0.90 were required to establish a standard for the average uniformity index. The equations for both I-CVI and S-CVI/Ave are shown in Equations 2 and 3, respectively.

\section{B) Equation 2}

Content validity index for item-level (1-CVI)

$$
=\frac{\text { The number of experts giving rating } 3 \text { or } 4}{\text { Total number of experts }}
$$




\section{C) Equation 3}

Content validity index for scale-level (S-CVI)

$$
=\frac{\text { The proportion of items given rating } 3 \text { or } 4}{\text { Total number of experts }} \times 100
$$

Overall scale average $\left(S-\frac{C V I}{A v e}\right)$

$$
=\frac{\text { The total of S- CVI for each expert }}{\text { Total number of experts }}
$$

\section{Phase 4 (Pre-testing)}

\section{Sampling and participant recruitment}

A cross-sectional study was conducted in this phase. The participants must be able to communicate and were literate in Bahasa Malaysia, and they were not reported to have a cognitive or a learning deficiency. A convenience sampling was applied and participants who met the criteria were recruited based on the ease of their volunteering, convenience, and accessibility to join this research project. Through a written consent process, 40 students aged 18 and 19 years old (mean of 18.45 , standard deviation of 0.315 ) from a college in Butterworth, Penang, were recruited. The participants' demographic profiles are summarised in Table 1.

Table 1. Participants' demographic profiles

\begin{tabular}{llcc}
\hline $\begin{array}{l}\text { Demograp } \\
\text { hic } \\
\text { profile }\end{array}$ & $\begin{array}{l}\text { Descripti } \\
\text { on }\end{array}$ & $\begin{array}{c}\text { Frequen } \\
\text { cy (n) }\end{array}$ & $\begin{array}{c}\text { Percenta } \\
\text { ge (\%) }\end{array}$ \\
\hline Gender & Male & 22 & 56 \\
& Female & 18 & 44 \\
Race & Malay & 32 & 81 \\
& Chinese & 6 & 15 \\
& Indian & 2 & 5 \\
& Sijil & 12 & 32 \\
& $\begin{array}{l}\text { pelajaran } \\
\text { Malaysia }\end{array}$ & & \\
Education & (SPM) & & \\
level & Sijil & 28 & 68 \\
& tinggi & & \\
& $\begin{array}{l}\text { pelajaran } \\
\text { Malaysia }\end{array}$ & & \\
& (STPM) & & \\
\hline
\end{tabular}

\section{Procedure}

A pre-testing evaluation form was administrated after the modules' delivery. The participants were asked to rate their agreement by indicating 'YES' or 'NO' on a few aspects; i) the statement related to the programme's objectives, ii) sufficiently specific and understandable content for each module, ii) suitability of activities and materials used, iii) clarity and layout of the content slides and iv) appropriateness of the programme's duration.

\section{Data analysis}

The percentage of agreement (\% of participants giving the rating YES) was calculated, and the score of $75 \%$ giving YES responses were recognised as having a good face-validity ${ }^{28}$.

\section{RESULTS}

\section{Content validation and module modification}

Table 2 summarises the results for content validation. The $\mathrm{CVR}$ values ranged from 0.6 to 0.99 , while the I-CVI values ranged between 0.7 and 1.0, indicating that some of the contents did not achieve the minimum acceptable level. The CVR and I-CVI values were relatively consistent with each other. The average value of CVI (S$\mathrm{CVI} /$ Ave) for all contents was 0.935 ; thus, this signified that the overall scale of the content slides was highly relevant. However, the expert panellists rated content slides numbers 3 and 13 as not being relevant and should be eliminated. In contrast to the validation rating, the content slide formatting and paragraphing, sentence structure, learning activities, and estimated duration of the programme obtained positive feedback from the experts. Nonetheless, several panellists suggested modifying the module's title to be more captivating for the audience. They also recommended simplifying and rephrasing the sentences used and translating the graphic and animation into Bahasa Malaysia.

Considering the experts' recommendations, a microscopic image of an impaired outer hair cell was not eliminated, but it was merged into the content slide that displayed the animation of outer hair cell damage. The reason for retaining this slide was that it might help the participants visualise the real conditions of the outer hair cell in the cochlear. A major revision included the addition of four slides into Module Three and Module Four. Two content slides in Module Three emphasised the nature of hearing loss (the definition of hearing loss and the cause of hearing loss), whereas the other two additional content slides in Module Four elaborated about two contributing risk-factors towards the severity of $\mathrm{NIHL}$ (the frequency of exposure and the distance from the source of noise). A content slide showing 
Table 2. The values of CVR and CVI for each content slide and the modifications performed

\begin{tabular}{|c|c|c|c|c|}
\hline Component & Content slides and layout & CVR & CVI & Modifications \\
\hline \multirow{4}{*}{ Introduction } & 1: Programme introduction & 0.8 & 0.9 & Remained \\
\hline & 2: Learning objectives & 0.99 & 1.0 & Remained \\
\hline & 3: The myths of hearing loss & $0.6^{*}$ & $0.7^{*}$ & Eliminated \\
\hline & 4: Introduction & 0.99 & 1.0 & Remained \\
\hline \multirow{5}{*}{$\begin{array}{l}\text { Module One } \\
\text { (Sound energy) }\end{array}$} & 5: Sound energy & 0.8 & 1.0 & Remained \\
\hline & 6: Sound vibration activity & 0.8 & 0.8 & Activity was revised \\
\hline & 7: Source of noise & 0.99 & 1.0 & $\begin{array}{l}\text { Remained but rearrange } \\
\text { into Module Four }\end{array}$ \\
\hline & 8: Hearing preventive measures & 0.99 & 1.0 & $\begin{array}{l}\text { Remained but rearrange } \\
\text { into Module Five }\end{array}$ \\
\hline & 9: Introduction & 0.99 & 1.0 & Remained \\
\hline \multirow{4}{*}{$\begin{array}{l}\text { Module Two } \\
\text { (Anatomy and } \\
\text { hearing } \\
\text { mechanism) }\end{array}$} & 10: Anatomy of the ear & 0.8 & 1.0 & Remained \\
\hline & 11: Video on hearing mechanism & 0.8 & 1.0 & Remained \\
\hline & $\begin{array}{l}\text { 12: Video on damaged outer hair } \\
\text { cells }\end{array}$ & 0.99 & 1.0 & \\
\hline & $\begin{array}{l}\text { 13: Microscopic image of damaged } \\
\text { outer hair cells }\end{array}$ & $0.6^{*}$ & $0.7^{*}$ & $\begin{array}{l}\text { rearranged into Module } \\
\text { Three }\end{array}$ \\
\hline \multirow{6}{*}{$\begin{array}{l}\text { Module Three } \\
\text { (Hearing loss) }\end{array}$} & 14: Introduction & 0.99 & 1.0 & Remained \\
\hline & 15: Degree of hearing loss & 0.8 & 0.9 & $\begin{array}{l}\text { A graphic of audiogram was } \\
\text { displayed }\end{array}$ \\
\hline & 16: Video on hearing loss simulation & 0.8 & 0.9 & Remained \\
\hline & 17: Adverse effects of hearing loss & 0.8 & 0.9 & $\begin{array}{l}\text { Effects of hearing loss on } \\
\text { quality of life were } \\
\text { included and discussed }\end{array}$ \\
\hline & & & & $\begin{array}{l}\text { Two content slides were } \\
\text { added: } \\
\text { i) Definition of hearing loss } \\
\text { ii) The causes of hearing } \\
\text { loss }\end{array}$ \\
\hline & 18: Introduction & 0.8 & 0.8 & Remained \\
\hline \multirow{5}{*}{$\begin{array}{l}\text { Module Four } \\
\text { (How loud the } \\
\text { sound) }\end{array}$} & 19: Decibels scale & 0.8 & 0.8 & New graphic replaced \\
\hline & 20: NIOSH noise meter activity & 0.99 & 1.0 & Remained \\
\hline & $\begin{array}{l}\text { 21: Factors contributing towards NIHL } \\
\text { 22: Permissible exposure level }\end{array}$ & 0.99 & 1.0 & Remained \\
\hline & 23: Sound measurement activity & 0.99 & 1.0 & Remained \\
\hline & & & & $\begin{array}{l}\text { Two content slides were } \\
\text { added: } \\
\text { i) Frequency of exposure } \\
\text { ii) Noise exposure and } \\
\text { distance }\end{array}$ \\
\hline Module & 24: Introduction & 0.99 & 1.0 & Remained \\
\hline Five(How to & 25: Hearing protection device & 0.99 & 1.0 & Remained \\
\hline $\begin{array}{l}\text { protect our } \\
\text { hearing) }\end{array}$ & 26: Earplug orientation activity & 0.99 & 1.0 & Remained \\
\hline $\begin{array}{l}\text { Quiz/learning } \\
\text { outcome }\end{array}$ & Sections $A$ and $B$ & 0.8 & 0.9 & $\begin{array}{l}\text { The layout was modified } \\
\text { into three sections; A, B } \\
\text { and C. }\end{array}$ \\
\hline
\end{tabular}

*Content slides eliminated as they did not meet the acceptable values of the content validity index. 
Table 3. Overview of the content slides, layout and timeframe for the final version of the Bisinglah BEB!

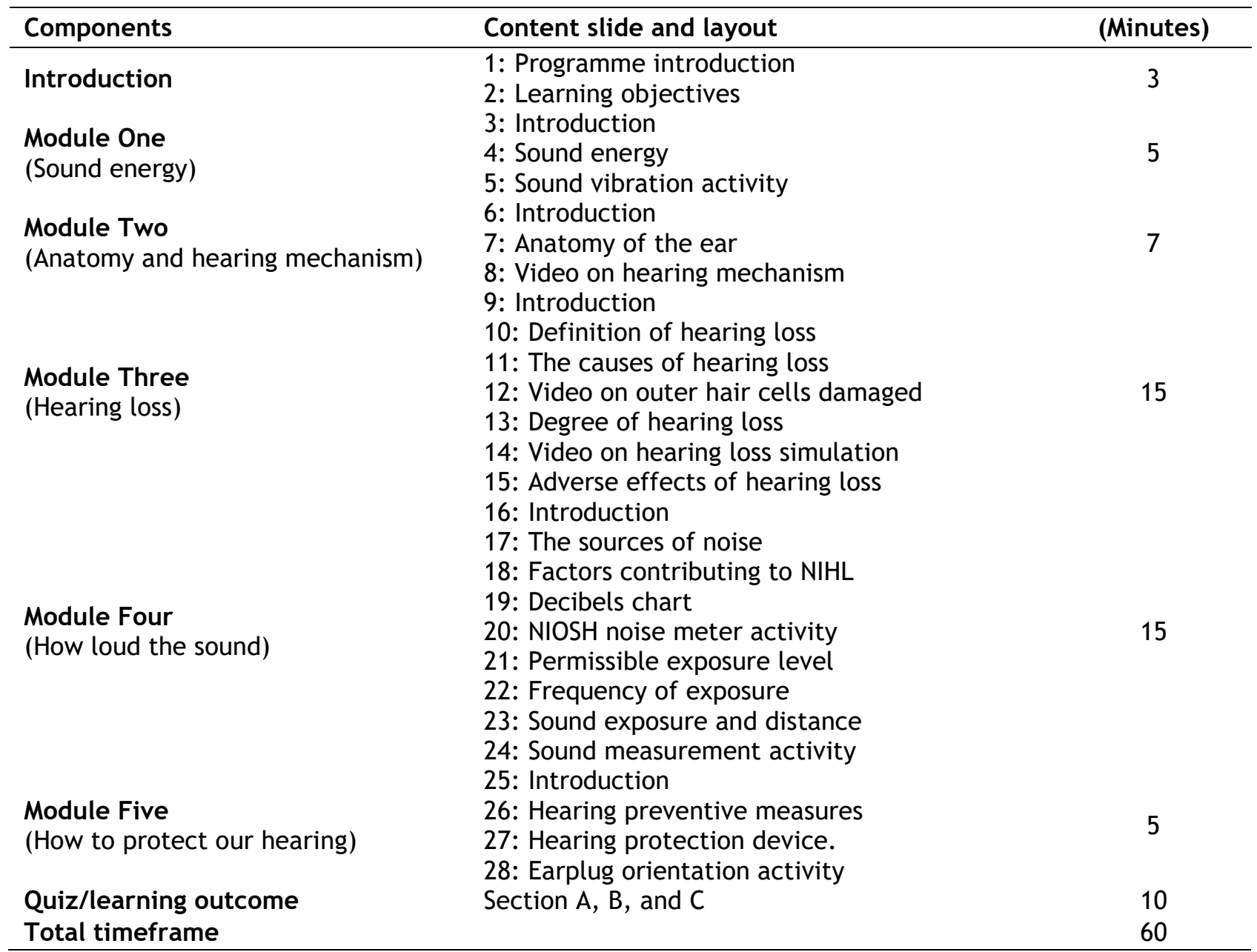

the degree of hearing loss was modified by adding an image of an audiogram with a speech spectrum to ensure participants would understand the correlation between the severity of hearing loss and communication impairment. The adverse effects of hearing loss on the quality of life, including social and emotional disturbances, were also included in a content slide discussing the

effects of NIHL. Lastly, through panel expert discussion, the sound energy activity using vocal cord vibrations was revised to an activity using a Malay percussion instrument (kompang) and green beans as it seemed to be more interactive with the audience. Upon modifications, the number of content slides increased to 28 slides

The layout of the learning outcome segment was modified into three sections; i) Section A consisted of five questions related to ear anatomy, ii) Section B consisted of ten closeended statements, and iii) Section $C$ consisted of five multiple-choice questions. In order to evaluate the participants' knowledge of noise exposure before and after the programme, all questions were created in accordance with the content slides. The duration of each slide and the overall final module are specified in Table 3.

\section{Pre-testing outcome}

All participants responded to the different aspects of the modules accordingly. The agreement and the interpretation of each facet of the module had achieved a minimum level of $75 \%$ (see Figure 3 ). These results indicated that an excellent level of agreement had been established. No revision was required after the pre-testing.

\section{DISCUSSION}

Content validity is mandatory in a research-based content development process. Even though the development of the contents of Bisinglah BEB! was an adaptation process, these contents still had to go through a validation process by a panel of experts and target groups. This was to ensure that the contents were comprehensively relevant. Although the process was a subjective evaluation, it could guide researchers to perform their study systematically ${ }^{29}$. Moreover, researchers could grasp the weaknesses of their contents by getting experts' opinions. Researchers could also evaluate how and what participants understood from their contents, as well as the conditions of the participants before a field study was conducted. 


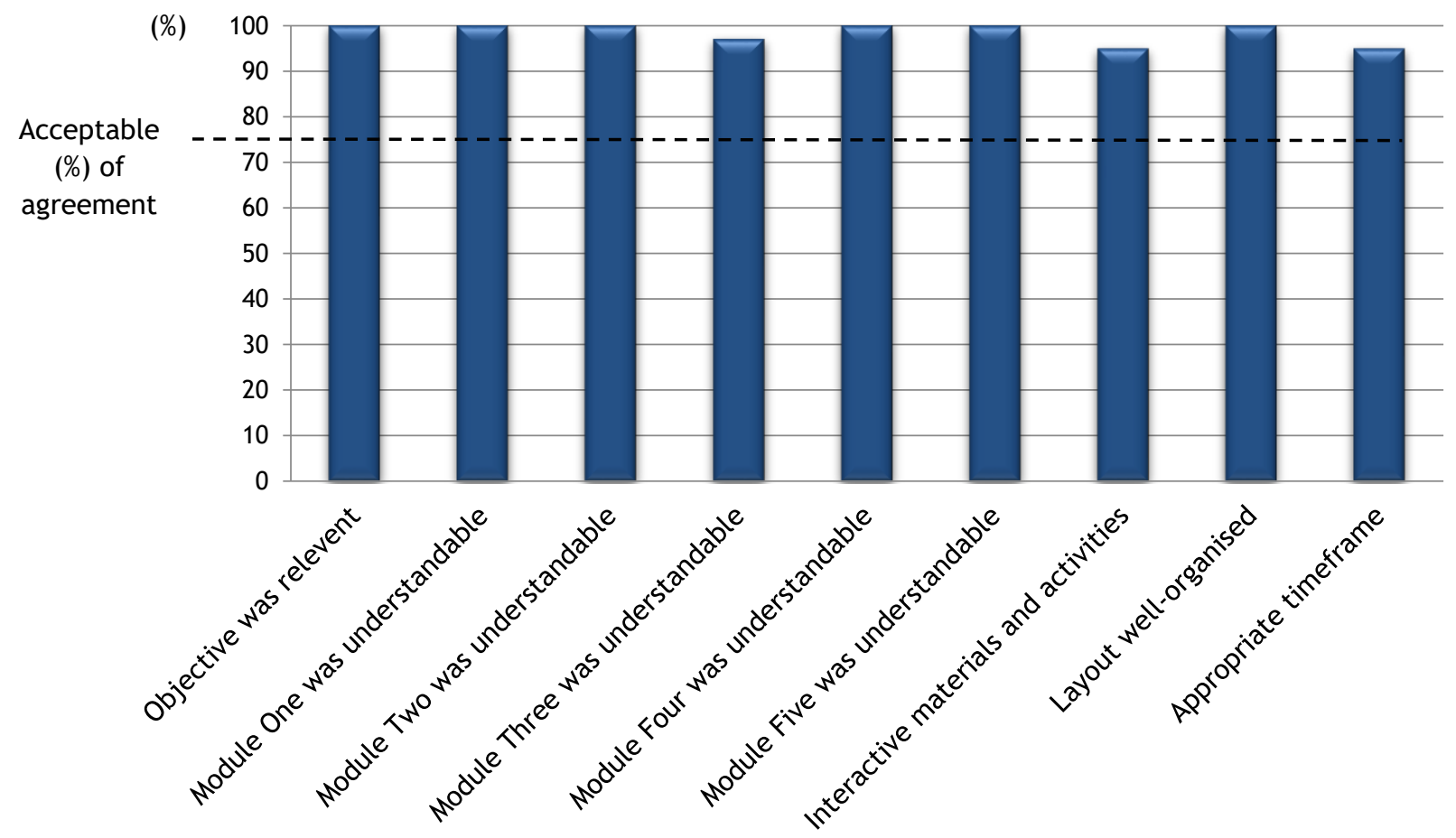

Figure 3. Participants' agreement for all aspects in the pre-testing

The contents and modules of Bisinglah BEB! were tailored to the needs of the Malaysian youth. For example, in Module One, participants were introduced to the concept of sound energy by conducting an activity using a Malay percussion instrument (kompang) and green beans in order to demonstrate the vibrations of sound energy. Kompang is a small drum made of bovine skin, usually that of cows. It is the most famous traditional instrument and is widely used in Malaysian schools for official functions (during the arrival of VIPs) ${ }^{30}$. In this case the use of a Malay traditional instrument could make the contents of

Module One relatable to the Malay culture. A supplementary video was used to ensure the participants had a better understanding and remembered critical points of the modules. Although the educational video was not as interactive as an entertainment video, it could be used to engage participants. This helped them easily comprehend the topics and enhanced their learning motivation 31 . Additionally, there were images of the anatomy of the ear and a decibel chart to elaborate on the contents in Module Two and Module Four, respectively. Learning through visuals in a classroom is very effective and has been broadly practiced in schools and universities around the world. The visual aids used in a lecture presentation do not only function to improve comprehension and motivate students to listen to the lecture, but also to reduce texts in presentation slides ${ }^{32}$. Interactive activities conducted in this programme, such as sound measurements and practical sessions on earplug use, were effective in improving participants' knowledge and attitudes for healthy hearing behaviours ${ }^{33}$. Moreover, providing free earplugs could also effectively encourage the participants to wear earplugs and to increase their earplug usage $^{34}$.

As this programme was developed only in Bahasa Malaysia, it was suggested for future research to translate the contents and modules of this programme into Mandarin and Tamil languages, since Malaysia is a multicultural country. This would reduce the language barriers among the youth. However, Bahasa Malaysia is recognised as the national language, and a majority of students know the language. For a more comprehensive and conclusive result, it was greatly recommended for future studies to assess the efficacy of the programme in changing participants' attitudes and knowledge towards noise in a larger pool of youth population in Malaysia.

\section{CONCLUSION}

Bisinglah $B E B$ ! produced a satisfactory content validation and an excellent pre-testing agreement. The values of the CVR and CVI fell within the acceptable ranges, which showed that the contents of the programme fulfilled the level of significance of content validity. The results in the pre-testing showed that all participants agreed that the programme was interactive and educational. The responses and comments from the participants were also positive, and the excellent outcome was proven in the pre-testing. It is hoped that the Bisinglah BEB! would be one of the on-going efforts in creating hearing awareness through formal education. It can be embedded either in the syllabuses of high schools or that of colleges and universities in Malaysia. 
Nevertheless, the effectiveness of the Bisinglah $B E B$ ! should be evaluated further before it can be fully implemented.

\section{ACKNOWLEDGMENT}

This study was funded by the Research Initiative Grant Scheme (Grant no: RIGS 16-136-0300). The authors are grateful to the expert panellists, college director, counsellor, and students for their contributions, willingness, and cooperation in this study. Special thanks to Signia Malaysia for the provision of goody bags and gifts for the participants.

\section{Conflicts of interest}

The authors and Signia Malaysia declare no conflict of interest.

\section{REFERRENCES}

1. Morata TC. Young people: Their noise and music exposures and the risk of hearing loss. Int J Audiol 2007; 46(3):111-2.

2. Danhauer JL, Johnson CE, Byrd A, et al. Survey of College Students on iPod Use and Hearing Health. J Am Acad Audiol 2009; 20(1): 5-27.

3. Zhao F, Manchaiah VK, French D, et al. Music exposure and hearing disorders: An overview. Int J Audiol 2010; 49(1):54-64.

4. Beach EF, Gilliver M, Williams W. Leisure noise exposure: participation trends, symptoms of hearing damage, and perception of risk. Int J Audiol 2013; 52(Suppl 1):20-5.

5. Carter L, Williams W, Black D, Bundy A. The leisure-noise dilemma: hearing loss or hearsay? What does the literature tell us? Ear Hear 2014; 35(5):491-505.

6. Jiang W, Zhao F, Guderley N, Manchaiah V. Daily music exposure dose and hearing problems using personal listening devices in adolescents and young adults: A systematic review. Int J Audiol 2016; 55(4):197-205.

7. World Health Organization (WHO). 1.1 billion people at risk of hearing loss. Media release 2015. Available from: https: / /www.who.int/mediacentre/news/ releases/2015/ear-care/en/ (accessed 3 February 2020).

8. Peng JH, Tao ZZ, Huang ZW. Risk of damage to hearing from personal listening devices in young adults. J Otolaryngol 2007; 36(3):181-5.
9. Lee GJC, Lim MY, Kuan AYW, et al. The music listening preferences and habits of youths in Singapore and its relation to leisure noise-induced hearing loss. Singapore Med J 2014; 55(2):72-7.

10. Widén SE, Holmes AE, Erlandsson SI. Reported hearing protection use in young adults from Sweden and the USA: Effects of attitude and gender. Int $J$ Audiol 2006; 45(5):273-80.

11. Warner-Czyz AD, Cain S. Age and gender differences in children and adolescents' attitudes toward noise. Int J Audiol 2016; 55(2):83-92.

12. Widén SE, Erlandsson SI. The influence of socio-economic status on adolescent attitude to social noise and hearing protection. Noise Health 2004; 7(25):5970.

13. Keppler H, Dhooge I, Vinck B. Hearing in young adults. Part I: The effects of attitudes and beliefs toward noise, hearing loss, and hearing protector devices. Noise Health 2015; 17(78):237-44.

14. Stansfeld S, Clark C. Health effects of noise exposure in children. Curr Envir Health Rpt 2015; 2(2):171-8.

15. Su JY, Guthridge S, He VY, Leach A. The impact of hearing impairment on early academic achievement in Aboriginal children living in remote Australia: a data linkage study. BMC Public Health 2020; 20(1):1-13.

16. Brown CS, Emmett SD, Robler SK, Tucci DL. Global hearing loss prevention. Otolaryngol Clin North Am 2018; 51(3):575-92.

17. Huddle MG, Goman AM, Kernizan FC, Foley DM, Price $C$, et al. The economic impact of adult hearing loss: A systematic review. JAMA Otolaryngo Head Neck Surg 2017; 143(10):1040-8.

18. Folmer RL. Hearing-Loss Prevention Practices Should Be Taught in Schools. Semin Hear 2008; 29(1):67-80.

19. ichey RC, Klein JD. Design and Development Research. In: Spector J., Merrill M., Elen J., Bishop M. (eds) Handbook of Research on Educational Communications and Technology. Springer, New York, NY: 2014.

20. Ishak KA, Ismail N, Rahmat S. ClassroomBased Educational Hearing Conservation Programme: Addressing the Contents and 
Challenges. International Journal of Allied Health Sciences 2021; 4(4): 1644-56.

21. Rosenstock IM, Strecher VJ, Becker MH. Social learning theory and health belief model. Health Educ Q 1988; 15(2):175-83.

22. Bandura A. Social foundations of thought and action: A social cognitive theory. Englewood Cliffs, NJ: Prentice-Hall:1986.

23. Rogers B, Meyer D, Summey C, et al. What makes a successful hearing conservation program?. AAOHN J 2009; 57(8):321-37.

24. Lass NJ, Woodford CM, Lundeen C, et al. A hearing-conservation program for a junior high school. Hearing J 1987a; 40:32-40.

25. Anderson KL. Hearing conservation in the public schools revisited. Semin Hear 1991; 12(4):340-64.

26. Lawshe $\mathrm{CH}$. A quantitative approach to content validity. Pers Psychol 1975; 28(4):563-75.

27. Lynn MR. Determination and quantification of content validity. Nurs Res 1986; $35(6): 382-5$.

28. Teles LM, Oliveira AS, Campos FC, et al. Development and validating an educational booklet for childbirth campanions. Rev EsC Enferm USP 2014; 48(6):977-84.
29. Zamanzadeh V, Ghahramanian A, Rassouli $M$, et al. Design and Implementation Content Validity Study: Development of an instrument for measuring Patient-Centered Communication. J Caring Sci 2015; 4(2):165-78.

30. thestar.com.my. Keeping the sounds of Kompang alive (updated 201929 April 2019; cited 19 January 2020]. Available from: https: / /www.thestar.com.my/news/natio $\mathrm{n} / 2019 / 04 / 29 /$ keeping-the-sounds-ofkompang-alive/

31. Wall K, Higgins S, Smith $\mathrm{H}$. 'The visual helps me understand the complicated things': Pupil views of teaching and learning with interactive whiteboards. $\mathrm{Br} J$ Educ Tech 2005; 36(5):851-67.

32. Ljubojevic M, Vaskovic V, Stankovic $S$, et al. Using supplementary video in multimedia instruction as a teaching tool to increase efficiency of learning and quality of experience. International Review of research in Open and Distance Learning 2014; 15(3):275-91.

33. Martin WH, Griest SE, Sobel JL, Howarth LC. Randomised trial of four noise-induced hearing loss and tinnitus prevention interventions for children. Int J Audiol 2014; 52(sup1):S41-S49.

34. Beach EF, Nielsen L, Gilliver M. Providing earplugs to young adults at risk encourages protective behaviour in music venues. Glob Health Promot 2016; 23(2):45-56. 